\title{
The development of sensitization to the psychomotor stimulant effects of amphetamine is enhanced in a novel environment
}

Received: 11 December 1993 / Final version: 8 June 1994

\begin{abstract}
Two experiments were designed to assess the effect of a "novel" environment on the development of sensitization to the psychomotor activating effects of $d$-amphetamine. In the first experiment, rats with a unilateral 6-hydroxydopamine lesion of the mesostriatal dopamine system received ten daily injections of amphetamine $(2 \mathrm{mg} / \mathrm{kg})$, either in their home cages or in novel test cages. The home and novel cages were physically identical (cylindrical transparent buckets), but one group lived and were tested in these cages, whereas the other group was transported from the stainless steel hanging cages where they lived to these novel test cages, for each test session. The first injection of amphetamine produced significantly more rotational behavior in animals tested in a novel environment than in animals tested at home. In addition, animals tested in a novel environment showed greater sensitization than animals tested at home, so the difference between the two groups was even more pronounced following the last injection. In a second experiment, locomotor activity was quantified in rats that received ten injections of either saline or $1.5 \mathrm{mg} / \mathrm{kg}$ amphetamine, in their home cages or in a physically identical novel environment. Again, there was a significantly greater locomotor response to the first injection of amphetamine, and greater sensitization, in animals tested in a novel environment than in animals tested at home. These data indicate that environmental factors can exert a large effect on the susceptibility to sensitization, and mechanisms by which this may occur are discussed.
\end{abstract}

Key words Conditioning Context-specific sensitization

\footnotetext{
A. Badiani (凶) · S. G. Anagnostaras · T. E. Robinson Department of Psychology and Neuroscience Program, The University of Michigan, Neuroscience Laboratory Building, 1103 East Huron St., Ann Arbor, MI , 48104-1687, USA
}

Environment-specific sensitization

Novelty $\cdot$ Novel environment $\cdot$ Stress

Rotational behavior - Locomotor activity $\cdot$ Rat

\section{Introduction}

Chronic intermittent treatment with $d$-amphetamine (amphetamine), as well as with a number of other addictive drugs, produces a long lasting sensitization to their behavioral activating effects (Robinson and Becker 1986; Kalivas and Stewart 1991). For example, the intensity of stereotyped behaviors induced by moderate doses of amphetamine increase with repeated drug exposure, as does the locomotor response to low doses of amphetamine. The reinforcing properties of amphetamine can also undergo sensitization (Piazza et al. 1989), which suggests that the neuroadaptations underlying sensitization may be involved in the development of addictive behaviors. Robinson and Berridge (1993) recently proposed, for example, that sensitization of the mesostriatal dopamine system, gated by associative learning, enhances the incentive salience attributed to drugs and drug-associated stimuli, and this leads to compulsive drug-seeking and drug-taking behavior.

The potential clinical relevance of sensitization has resulted in considerable interest in the phenomenon, and in the factors that influence the susceptibility to sensitization (for a recent review see: Stewart and Badiani 1993). A number of these factors have been identified, including environmental factors associated with drug administration. For example, under some experimental conditions the expression of sensitization can come under conditioned stimulus control, and in such cases sensitization is observed only when a drug challenge is given in an environment previously paired with drug treatments (Tilson and Rech 1973; Hinson and Poulos 1981; Post et al. 1981; Vezina and Stewart 1984). This phenomenon is known as environment- or 
context-specific sensitization. Environmental factors may influence the development and the expression of sensitization to drugs in other ways as well (Hirabayashi and Alam 1981; Willner et al. 1992; Einat and Szechtman 1993). Of particular relevance here is the observation that how familar an environment is may affect the behavioral response to drugs. For example, there have been a number of studies showing that repeated pre-exposures or pre-habituation to a test environment alters the acute behavioral response to amphetamine (Russel and Pihl 1978; Bardo et al. 1990) and cocaine (Kiyatkin 1992).

In a series of unpublished experiments concerning the contextual control of amphetamine sensitization (Anagnostaras et al. 1993) we made the serendipitous observation that the rate of sensitization appeared to be very different in animals that received repeated injections of amphetamine in the environment in which they lived ("home"), than in animals that received repeated injections of amphetamine in a "novel" test environment. A review of the literature revealed no studies directly comparing either the acute response to amphetamine or the development of sensitization, in animals given the drug in a home versus novel environment, when the physical characteristics of the two environments were held constant. To make this comparison it is necessary, of course, that the home and novel environments be physically identical, because variations in the physical characteristics of the environment (e.g., size, shape, bedding etc.) can have large effects on the behavioral actions of drugs (Ellinwood and Kilbey 1975; Schallert et al. 1980; Hirabayashi and Alam 1981; Beck et al. 1986; Sullivan et al. 1992; Terlouw et al. 1992; Willner et al. 1992; Einat and Szechtman 1993). In addition, prior studies on the contextual control of sensitization do not address this issue because these experiments concern how contextual cues previously associated (or not associated) with drug administration influence the subsequent expression of sensitization; not how home versus novel environments influence the development of sensitization.

The purpose of this study, therefore, was to directly compare the development of sensitization in a home versus novel environment, by using home and novel test cages that were physically identical. This comparison is important for two reasons: i) to understand the phenomenon of sensitization we need to understand the variables that influence susceptibility to sensitization, including environmental factors; ii) the two drug treatment protocols compared here are often used in different studies of sensitization, and better integration of the literature necessitates a direct comparison.

Obviously, after repeated exposures, the "novel" environment will be somewhat less novel from a "cognitive" point of view, although neuroendocrine responses are not necessarily diminished (Hennessy and Levine 1977; Hennessy 1991).

\section{Experiment 1: sensitization of rotational behavior}

In the first experiment the effects of chronic amphetamine on rotational behavior were studied in rats with a unilateral lesion of the mesostriatal dopamine system (Ungerstedt and Arbuthnott 1970). The quantification of the rotational response to amphetamine as an index of amphetamine's psychomotor activating effect offers two major advantages over the more traditional quantification of locomotor activity. First, the dose-response curve for rotational behavior in rats with a unilateral 6-OHDA lesion is linear over a wide range of doses of amphetamine (Ungerstedt and Arbuthnott 1970). Thus, with sensitization, a progressive increase in drug effect is seen as a progressive increase in rotational behavior (Robinson 1984). In contrast, the dose-response curve for amphetamineinduced locomotor activity in naive rats is very complex, and the behavioral response is often highly variable (Segal and Schuckit 1983). Thus, with locomotor activity, sensitization can be studied only over a narrow range of doses, and a progressive increase in drug effect is not necessarily characterized by a progressive increase in locomotor activity (due, for example, to the emergence of increasingly complex stereotyped behaviors). Second, exposure to a novel environment by itself produces negligible rotational behavior (Anagnostaras et al. 1993), whereas this induces a marked increase in locomotor activity. Therefore, rotational behavior is particularly suitable for studying the interaction between effects of amphetamine and novelty.

Materials and methods

Subjects

Male Holtzman/Sprague-Dawley rats, weighing $175-250 \mathrm{~g}$ at the beginning of the experiment, were purchased from Harlan Sprague Dawley (Indianapolis, Ind., USA). They were individually housed in a room with a 14-h light/10-h dark cycle (lights on from 0600 to 2000 hours), and had ad libitum access to food and water.

Drugs

6-Hydroxydopamine (2,4,5-trihydroxyphenethylamine) hydrobromide (6-OHDA) was freshly dissolved $(2 \mathrm{mg} / \mathrm{ml})$ in a cold solution of $0.9 \mathrm{mg} / \mathrm{ml} \mathrm{NaCl}$ (saline) and $0.1 \mathrm{mg} / \mathrm{ml} l$-ascorbic acid. Atropine methyl nitrate was dissolved $(0.5 \mathrm{mg} / \mathrm{ml})$ in saline and administered IP $(0.2 \mathrm{mg} / \mathrm{kg})$. Desipramine hydrochloride (DMI) was dissolved $(15 \mathrm{mg} / \mathrm{ml})$ in distilled water and given IP $(15 \mathrm{mg} / \mathrm{kg})$. Apomorphine hydrochloride was freshly dissolved $(0.1 \mathrm{mg} / \mathrm{ml})$ in saline and $0.01 \mathrm{mg} / \mathrm{ml} l$-ascorbic acid and injected subcutaneously in the neck $(0.05 \mathrm{mg} / \mathrm{kg}) . d$-Amphetamine sulfate (AMPH) was dissolved $(1 \mathrm{mg} / \mathrm{ml})$ in saline and administered IP $(2.0 \mathrm{mg} / \mathrm{kg}$, weight of the salt). All these drugs were purchased from Sigma (St Louis, Mo., USA). Sodium pentobarbital was dissolved $(64.8 \mathrm{mg} / \mathrm{ml})$ in a $10 \%$ 
ethanol solution (Butler Company, Columbus, Ohio, USA) and was given IP $(52 \mathrm{mg} / \mathrm{kg})$.

\section{Surgical and screening procedures}

One week after their arrival in the animal colony, the rats received a unilateral 6-OHDA lesion of the mesostriatal dopamine system using procedures similar to those described by Robinson (1984). Briefly, animals were pretreated with desipramine to protect noradrenergic terminals (Breese and Traylor 1971) and then anaesthetized with sodium pentobarbital. Using standard stereotaxic techniques, a 29 gauge stainless steel cannula was lowered into the medial forebrain bundle, and this was used to deliver $8 \mu \mathrm{g} 6$-OHDA in $4 \mu \mathrm{l}$ of a saline-ascorbate solution over an 8-min period. The animals were allowed to recover from surgery for at least 2 weeks and were then tested with $0.05 \mathrm{mg} / \mathrm{kg}$ apomorphine, to assess the development of dopamine receptor supersensitivity (denervation supersensitivity), as expressed by the appearance of contraversive rotational behavior. Denervation supersensitivity is a good indicator of the size of the lesion since it occurs only after $90-95 \%$ of dopamine terminals are destroyed (Hefti et al. 1980a, b). Animals that made fewer than 100 rotations over a 30 -min test were excluded from the study.

\section{Procedures}

Thirty rats passed the apomorphine screen and were used in this experiment. Ten of them (group HOME) were housed in a testing room in cylindrical ( $25 \mathrm{~cm}$ diameter), transparent buckets equipped with drinking tubes. The floors of these buckets were covered with ground corn cob bedding. An additional ten rats (group NOVEL) were housed in stainless steel hanging cages located in the main animal colony room. The waste trays below these cages were covered with pine wood shavings. After 1 week of habituation to these housing conditions. NOVEL rats were transferred every day from their home cages in the animal colony to the test room, and placed in plastic buckets identical (including the presence of ground corn cob bedding, food, and water) to those in which HOME rats lived. They then received an IP injection of $2.0 \mathrm{mg} / \mathrm{kg}$ amphetamine (group AMPH-NOVEL). This procedure was repeated on 10 consecutive days. At the same time HOME rats received $2.0 \mathrm{mg} / \mathrm{kg}$ amphetamine in their home cages (group AMPH-HOME). Therefore, the environments in which HOME and NOVEL rats received amphetamine were physically identical, but this was a novel environment for one group and the home environment for the other group. To quantify the effects of the injection procedure plus exposure to the NOVEL environment alone, an additional group of ten rats received daily injections of saline in the NOVEL cages (group SAL).

Each test session lasted $90 \mathrm{~min}$, after which time NOVEL rats were returned to their hanging cages in the animal colony. The behavior of the animals was videotaped during the first, second, sixth and tenth test sessions, and rotational behavior was quantified by viewing the videotapes. One rotation was defined as a complete $360^{\circ}$ turn.

\section{Data analysis and statistics}

Overall group differences were first analyzed with a two-way ANOVA with repeated measures (Test environment, two levels, HOME and NOVEL; by Test session, four levels). Group differences on the first test session were assessed with a planned Student's $t$ test. To assess the development of sensitization over test sessions, linear regression analyses were performed for each individual rat and for each treatment group (a positive slope indicates sensitiza- tion, and a high slope coefficient indicates rapid sensitization). A Student's $t$-test was used to determine if there was a significant difference between the two groups in the slope coefficients calculated for individual rats (i.e., if there was a difference in the rate of sensitization).

On the basis of the rotational response to the first injection of amphetamine the groups were divided into two subgroups, corresponding to the rats with rotational scores below (LOW) or above (HIGH) the median score. These were analyzed first by an overall two-way ANOVA with repeated measures for one factor (Group, four levels, HOME-LOW, HOME-HIGH, NOVEL-LOW, and NOVEL-HIGH, by Test session). Group differences in the first test session were assessed by a planned one-way ANOVA (Group, four levels), followed by Fisher's PLSD tests. In addition, linear regression analyses were performed as described above, and group differences in slope coefficients were evaluated using a one-way ANOVA followed by Fisher's PLSD tests.

\section{Results}

Figure 1 shows the effects on rotational behavior of repeated injections of saline (SAL) given in a novel environment, and of amphetamine (AMPH) given in either a novel environment or at home. A two-way ANOVA with repeated measures for one factor resulted in significant effects of Test environment $(F 1,18=22.47, P<0.001)$, Test session $(F 3,54=51.87$, $P<0.0001)$, and a Test environment $\times$ Test session interaction $(F 3,54=10.87, P<0.0001)$. The simple main effect of Test session was significant in both group AMPH-HOME $(F 3,54=8.04, P<0.001)$ and AMPHNOVEL $(F 3,54=54.7, P<0.0001)$. The following major findings are illustrated in Fig. 1. i) An injection of saline followed by exposure to the novel environment produced negligible rotational behavior. ii) The first injection of amphetamine produced an increase in rotational behavior in both group AMPH-HOME and group AMPH-NOVEL (compare their response to group SAL, Fig. 1), but the magnitude of this effect was significantly greater in those animals that received amphetamine in group AMPH-NOVEL $(t=3.62$, $P=0.002$ ). iii) Repeated injections of amphetamine produced a progressive increase in amphetamineinduced rotational behavior (sensitization) in both group AMPH-HOME (slope coefficient: $30.9, P<0.01$; $r^{2}=0.98 ;$ mean $r^{2}$ for individual rats $=0.71 \pm 0.12$ ) and group AMPH-NOVEL (slope coefficient: 79.7, $P=0.02 ; r^{2}=0.96 ;$ mean $r^{2}$ for individual rats $=$ $0.92 \pm 0.02$ ). iv) There were significant group differences in the rate of amphetamine sensitization. The mean slope coefficient of the regression lines calculated for individual animals in group AMPH-NOVEL was significantly greater than in group AMPH-HOME $(79.67 \pm 10.72$ versus $30.93 \pm 7.45 ; t=3.73, P<0.002)$.

Figure 2 shows the same data as Fig. 1, but after the groups were subdivided based on their response to the first injection of amphetamine (i.e., above and below the median). This analysis establishes that the group differences in the rate of sensitization shown in Fig. 1 


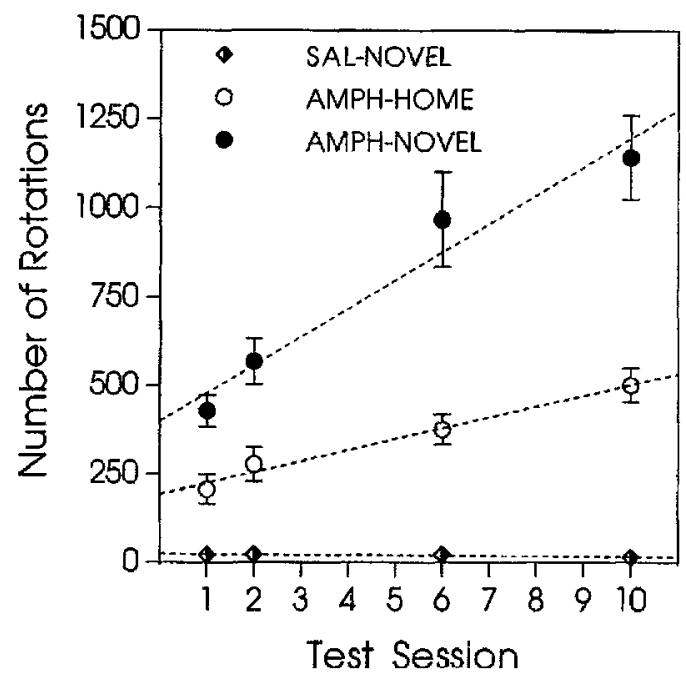

Fig. 1 The mean $( \pm S E)$ number of full rotations during the 1 st, 2nd, 6th, and 10th test sessions for animals that received amphetamine $(2.0 \mathrm{mg} / \mathrm{kg}, \mathrm{IP})$ either at home (AMPH-HOME, open circles) or in a novel test environment (AMPH-NOVEL, filled circles). The data from a group given saline ( $S A L$, hatched diamonds) are shown for comparison purposes, and are not included in the statistical analysis. The dashed lines represent linear regressions of the mean number of full rotations over test sessions for groups AMPHHOME and AMPH-NOVEL

are not a simple function of group differences in the initial response to amphetamine.That is, the initial response to amphetamine does not necessarily predict susceptibility to sensitization (Robinson 1988). An initial two-way ANOVA with repeated measures for one factor (Group by Test session) resulted in a significant main effect of Group $(F 3,16=11.99, P<0.001)$, Test session $(F 3,48=59.64, P<0.0001)$, and a Group $\times$ Test session interaction $(F 9,48=5.73, P<0.0001)$. The simple main effect of Test session was significant in groups HOME-LOW, NOVEL-LOW, and NOVEL-HIGH (all $F$ s $3,48<10.35$, all $P$ s $<0.001$ ), but not in group HOME-HIGH $(F 3,48=1.46, P>0.2)$. The analyses of regression indicated development of sensitization in group HOME-LOW (slope coefficient: 45.8, $P=0.01$; $r^{2}=0.98$; mean $r^{2}$ for individual rats $=0.89 \pm 0.05$ ), NOVEL-LOW (slope coefficient: 69.5, $P=0.003$; $r^{2}=0.99$; mean $r^{2}$ for individual rats $=0.95 \pm 0.03$ ), and NOVEL-HIGH (slope coefficient: $89.8, P=0.047$; $r^{2}=0.91 ;$ mean $r^{2}$ for individual rats $=0.90 \pm 0.02$ ), but not in group HOME-HIGH (slope coefficient: 16.0, $P=0.077 ; r^{2}=0.84 ;$ mean $r^{2}$ for individual rats $=$ $0.53 \pm 0.2$ ). The important group comparisons, in which the initial response to amphetamine was dissociated from sensitization, include the following. i) Groups HOME-HIGH and NOVEL-LOW made the same number of rotations during the first test session (Fisher's PLSD test, $P=0.78$ ), but the rate of sensitization for group NOVEL-LOW was significantly greater than for group HOME-HIGH (mean slope coefficients: $69.55 \pm 15.74$ versus $16.04 \pm 7.29 ; P=0.001$,

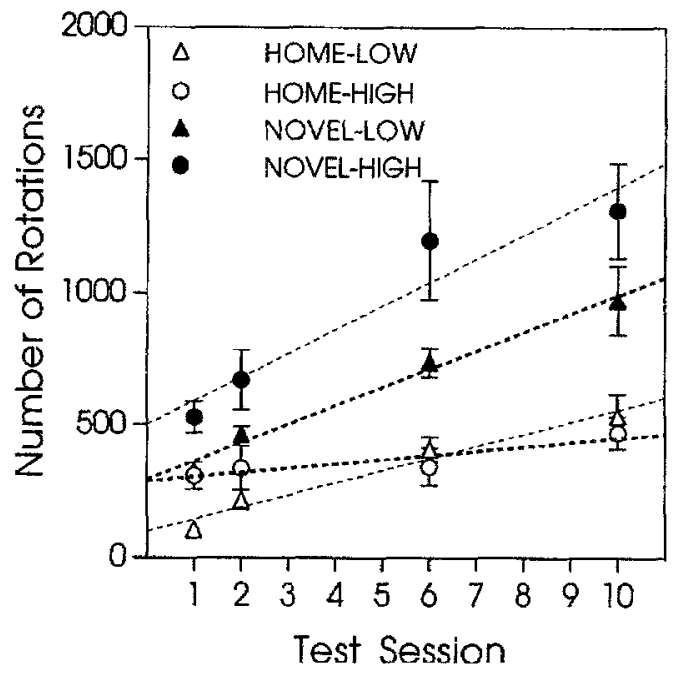

Fig. 2 The mean ( \pm SE) number of full rotations during the 1st, 2nd, 6th and 10th test sessions in animals given amphetamine, after the groups were subdivided on the basis of their initial response to amphetamine. Each group was divided in two subgroups, corresponding to the rats with rotational scores below (HOME-LOW, open triangles and NOVEL-LOW, filled triangles) or above (HOME-HIGH, open circles and NOVEL HIGH, filled circles) the group median. The dashed lines represent linear regressions of the mean number of full rotations over test sessions for the four groups

Fisher's PLSD tests following a significant one-way ANOVA, $F 3,16=6.66, P=0.004)$. ii) Group NOVELHIGH made significantly more rotations than group NOVEL LOW during the first test session (Fisher's PLSD test, $P<0.003$ ), but these groups did not differ in their rate of sensitization (mean slope coefficients: $89.79 \pm 14.77$ versus $69.55 \pm 15.75$, Fisher's PLSD test, $P=0.26$ ). iii) group HOME-LOW made fewer rotations than group HOME-HIGH during the first test session (Fisher's PLSD test, $P=0.0026$ ), but the two groups did not differ significantly in their rate of sensitization (mean slope coefficients: $45.82 \pm 9.27$ versus 16.04 \pm 7.29 ; Fisher's PLSD test, $P=0.106$ ).

\section{Experiment 2: sensitization of locomotor activity}

In experiment 1 amphetamine produced more robust sensitization of rotational behavior when given to rats as they were placed in a novel environment, than when given to rats in a physically identical environment, but who lived in that environment. To determine if this effect is unique to rotational behavior, or to rats with a 6OHDA lesion, the experiment was repeated using locomotor activity in intact rats as the dependent measure.

Materials and methods

Subjects

See experiment 1. 


\section{Procedures}

Ten rats (group HOME) were individually housed in stainless steel hanging cages that are described in more detail below. The trays below these cages were covered with pine wood shavings. Ten other rats (group NOVEL) were housed in cylindrical transparent plastic buckets similar to those used in experiment 1 , and the floor of each bucket was covered with ground corn cob bedding. The two home environments were, therefore, very different, although both types of cages were located in the same room. After 1 week of habituation to these housing conditions, NOVEL rats were transferred every second day to locomotor activity cages identical (including the presence of food and water) to those in which HOME rats lived. They then received an IP injection of either $1.5 \mathrm{mg} / \mathrm{kg}$ amphetamine (AMPH-NOVEL, $n=5$ ) or saline (SAL-NOVEL, $n=5$ ). At the same time HOME rats received $1.5 \mathrm{mg} / \mathrm{kg}$ of either amphetamine or saline in their home cages (AMPH-HOME, $n=5$; and SALHOME, $n=5$ ). This procedure was repeated every other day for a total of ten injections. Each test session lasted 90 min, after which time NOVEL rats were returned to their home cages (i.e., the buckets).

\section{Locomotor behavior}

Locomotor activity was quantified in stainless steel hanging cages $(41 \times 24 \times 18 \mathrm{~cm})$, half of which served as home for group HOME rats. The cages were equipped with two photoconductive infrared cells and photobeams mounted $5.0 \mathrm{~cm}$ above the floor along the long axis of the cage, $25.2 \mathrm{~cm}$ apart from each other. The electronic signal generated by breaking a light beam was sent through an SS100 Plus Simplified Digital I/O board, to a Commodore 64 microcomputer for the collection and analysis of the data. The computer was programmed such that after one photobeam was interrupted, and a single count registered, no more counts could be registered from this beam until the other beam had been interrupted. Therefore, the number of counts in this apparatus reflect the number of "crossovers" (locomotion) from one end of the cage to the other, and not the repetitive interruption of one of the beams. Photobeam interruptions were recorded in 5-min bins.

\section{Data analysis and statistics}

Group differences in the total number of photobeam interruptions recorded in each 90-min session were analyzed first with a threeway ANOVA with repeated measures (Test environment by Drug treatment by Test session). Group differences in the first test session were assessed by a planned one-way ANOVA (Group, four levels), followed by Fisher's PLSD tests. In addition, linear regression analyses were performed as described above, and group differences in slope coefficients were evaluated using a one-way ANOVA followed by Fisher's PLSD tests.

\section{Results}

Figure 3 shows the mean locomotor response following each of ten successive injections of saline or amphetamine, given either in the home cages or in a novel test environment. A three-way ANOVA with repeated measures for one factor resulted in a significant effect of Test environment $(F 1,16=53.91, P<0.0001)$, Treatment $(F 1,16=80.92, \quad P<0.0001)$, Test session $(F 9,144=5.46, P<0.0001)$, Test environment $\times$ Treat- ment interaction $(F 1,16=7.68, \quad P<0.02), \quad$ Test environment $\times$ Test session interaction $(F 9,144=2.52$, $P=0.01$ ), and Treatment $\times$ Test session interaction $(F 9,144=11.17, P<0.0001)$. The Test environment $\times$ Treatment $\times$ Test session interaction was not quite statistically significant $(F 9,144=1.73, P=0.087)$. The simple main effect of test session was significant in groups SAL-NOVEL, AMPH-HOME, and AMPHNOVEL (all $F \mathrm{~s} 9,144>3.38$, all $P \mathrm{~s}<0.001$ ), but not in group SAL-HOME $(F 9,144=0.04, P>0.75)$. Figure 4 shows the results of linear regression analyzes conducted on the locomotor activity scores.

\section{Effect of saline}

An injection of saline at home (group SAL-HOME) produced very little locomotor behavior. In contrast, animals that received saline and then were placed in a novel environment (SAL-NOVEL) showed a marked increase in locomotor activity, relative to SAL-HOME animals (Fig. 3). An ANOVA on the data of the first test session showed significant group differences $(F 3,16=60.16, P<0.0001)$, and group SAL-NOVEL was significantly more active than group SAL-HOME (Fisher's PLSD test, $P<0.0001$ ). In group SALHOME there was no change in the response to saline between the first and tenth test sessions, whereas there was a linear decrease in locomotor activity in group SAL-NOVEL over the first four test sessions, after which time it remained stable (see Fig. 4).

\section{Effect of amphetamine}

As predicted from experiment 1 , the first injection of amphetamine produced a significantly greater increase in locomotor activity in group AMPH-NOVEL than in group AMPH-HOME (or in the saline groups; Fisher's PLSD tests, all $\left.P_{\mathrm{S}}<0.0001\right)$. Repeated injections of amphetamine produced a linear increase in locomotor activity in group AMPH-HOME, but more complicated changes in behavior in group AMPH-NOVEL (Fig. 4). Over the first three test sessions there was a linear decrease in AMPH-induced locomotor activity in group AMPH-NOVEL, followed by a linear increase in locomotor activity over the remaining test sessions. This makes a comparison of the rate of sensitization in groups AMPH-NOVEL and AMPH-HOME somewhat complicated. It can be seen in Fig. 4, however, that in groups AMPH-NOVEL and group SAL-NOVEL there was a parallel decrease in locomotor activity over the first few test sessions (there was no difference in their slope coefficients at this time). This suggests that the decrease in locomotor activity seen in AMPH-NOVEL animals was due, not to a decreasing effect of amphetamine, but to habituation to the injection procedure and exposure 


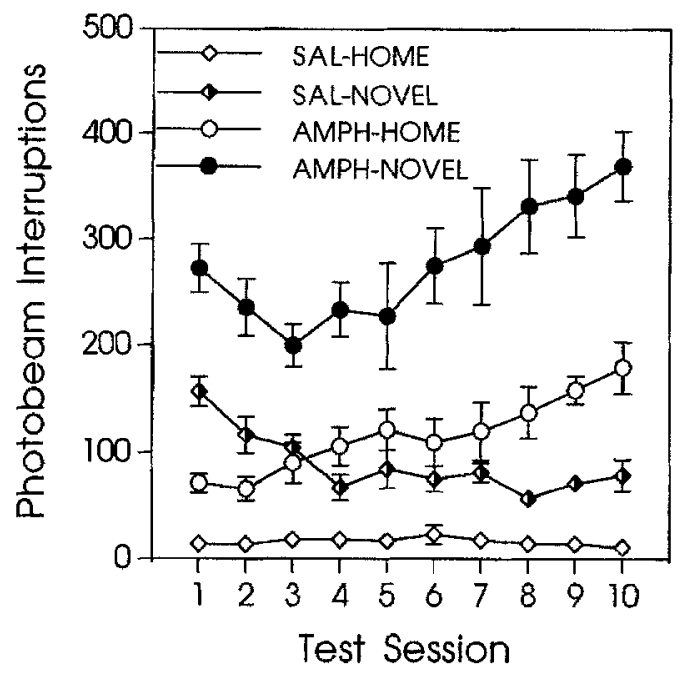

Fig. 3 The mean (+SE) number of crossovers (photobeam interruptions) during ten test sessions for animals that received saline $(S A L)$ or $1.5 \mathrm{mg} / \mathrm{kg}$ amphetamine IP $(A M P H)$ either at home $(S A L$ HOME, open diamonds and AMPH-HOME, open circles) or in a novel test environment (SAL-NOVEL, hatched diamonds and AMPH-NOVEL, filled circles)

to a novel environment (i.e., habituation to "novelty" per se). That is, the relatively high locomotor response on the first few test sessions may be due to the summation of a high unconditioned response to "novelty" alone (as seen in the SAL-NOVEL animals), and the response to amphetamine (or to the "novelty"-amphetamine interaction). Figure 4 shows that when the regression analysis was limited to the last eight test sessions the rate of sensitization in group AMPH-NOVEL was significantly greater than in group AMPH-HOME (as indicated by a significant difference in their slope coefficients).

\section{Discussion}

Both the acute psychomotor activating effects of amphetamine, and the development of sensitization to these effects, were greater if amphetamine was given in a novel environment (NOVEL) than in the home environment (HOME). Two different behavioral measures of the psychomotor activating effects of amphetamine were used: rotational behavior in rats with a unilateral 6-OHDA lesion (experiment 1), and locomotor activity in naive rats (experiment 2). In both cases, rats given amphetamine in a novel environment showed a greater behavioral response to the first injection of amphetamine than rats given amphetamine in their home environment. Furthermore, repeated intermittent injections of amphetamine resulted in a progressive increase in rotational behavior and locomotor activity (sensitization) in both the novel and home environments, but the rate of sensitization was greater if the drug was given in a novel environment. It is also interesting that the effects of environment on the acute response to amphetamine appeared to be independent of its effects on the susceptibility to sensitization. When the HOME and NOVEL groups were subdivided into two subgroups that did not differ in their acute response to amphetamine (HOME-HIGH and NOVEL-LOW), animals given amphetamine in a novel environment still showed greater sensitization than animals given amphetamine at home. This is consistent with other reports that the acute response to psychomotor stimulants does not necessarily predict susceptibility to sensitization (Robinson 1988).

It is interesting that the notion that the acute psychomotor activating effect of amphetamine and amphetamine sensitization are enhanced if animals receive drug injections in a novel environment is already accepted to some extent, because we know of no studies prior to this report that provide direct experimental evidence to support this claim. For example, Willner et al. (1992, p. 43) state: "sensitization is greater in animals that experience the drug in the testing environment then in animals that experience the drug in their home cage (Ellinwood and Kilbey 1975; Ellinwood 1971; Hinson and Poulos 1981; Mattingly and Gotsick 1989; Mazurski and Beninger 1987; Post et al. 1981; Schiff 1982; Stewart and Vezina 1987,1991; Tilson and Rech 1973; Vezina and Stewart 1984)", and Einat and Szechman (1993, p. 599) state: "psychomotor stimulants produce greater enhancement of locomotion when administered repeatedly in the test environment (activity monitors) than when administered in the home cage (Cools et al. 1991; Hoffman and Wise 1992; Post et al. 1981; Stewart and Vezina 1988; Weiss et al. 1989)". The problem with this conclusion, however, is that none of the studies cited compared the influence of home versus novel environments on the development of sensitization. The effect of "environment" in most of these studies is actually an example of conditioned stimulus control over the expression of sensitization.

There are many reports that the expression of sensitization can come under conditioned stimulus (CS) control. In such studies typically one group of animals (Paired) is transported from the home cage to a unique test environment, where animals receive drug treatments (saline is usually given at home). A second group of animals (Unpaired) receives saline in the test environment and the drug at home. Control animals receive saline both in the test environment and at home. The influence of drug treatments (and environment) is assessed on a "test day", when all animals receive a challenge injection of the drug in the test environment. In most studies of this kind robust sensitization is seen in the Paired group, but not the Unpaired group. It needs to be emphasized that in the above-mentioned studies the development of sensitization in the home environment was not assessed (the animals were observed in a test environment, not at home), and there- 


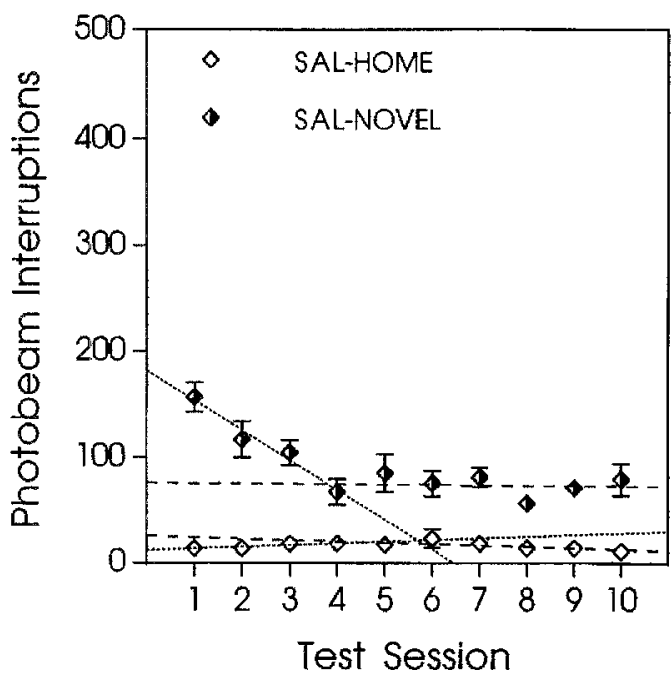

Fig. 4 Left panel. The lines represent the linear regression of the mean number of photobeam interruptions over test sessions for groups SAL-HOME (open diamonds) and SAL-NOVEL (hatched diamonds). Separate regression lines were calculated for sessions 1-4 (dotted lines) and sessions 4-10 (dashed lines). In group SAL-HOME there was no difference in the slope coefficients calculated for sessions $1-4$ vs. $4-10(1.71 \pm 1.75$ vs. $-0.79 \pm 0.6 ; t=1.17, P=0.31)$, and the mean slope coefficients did not differ from zero (sessions 1-10: $t=1.153, P=0.31$ ). In contrast, in group SAL-NOVEL the change in slope coefficients between sessions $1-4$ vs. 4-10 was significant $(-28.08 \pm 6.42$ vs. $-0.28 \pm 2.18$; paired $t$-test, $t=3.96$, $P<0.02$ ). In group SAL-NOVEL there was, in fact, a linear decrease in locomotor activity over the first four test sessions (slope coefficient: $-28.1, P=0.018 ; r^{2}=0.96$; mean $r^{2}$ for individual rats $=0.74 \pm 0.15$ ), but no change in locomotor activity between sessions 4 and 10 (the mean slope coefficient did not differ from zero, $t=0.99, P=0.38$ ). Right panel. The lines represent the linear regression of the mean number of photobeam interruptions over treatment days for groups AMPH-HOME (open circles) and AMPH-NOVEL (filled circles). Separate regression lines were cal-

fore, this design does not allow one to make any inferences about the relative rate or extent of sensitization in the home versus novel (paired) environment. The results of studies using a classical conditioning paradigm only allow one to make inferences about the influence of contextual cues previously associated (or not associated) with drug administration on the expression of sensitization; i.e., on the conditioned (contextual) stimulus control over the expression of sensitization. Furthermore, in those few studies in which the drug response was assessed in both a home and a novel environment, the two environments were physically different (e.g., Sahakian et al. 1975; Einat and Szechtman 1993). This precludes any direct comparison of either the acute response to the drug, or the development of sensitization, because the physical characteristics of an environment have a large effect on the quantity and quality of behaviors expressed in response to a drug (Ellinwood and Kilbey 1975; Sahakian and Robbins 1975; Schallert et al. 1980; Hirabayashi and Alam 1981; Beck et al. 1986; Sullivan et al. 1992; Terlouw et al. 1992; Willner et al. 1992; Einat and Szechtman 1993). The present report is the

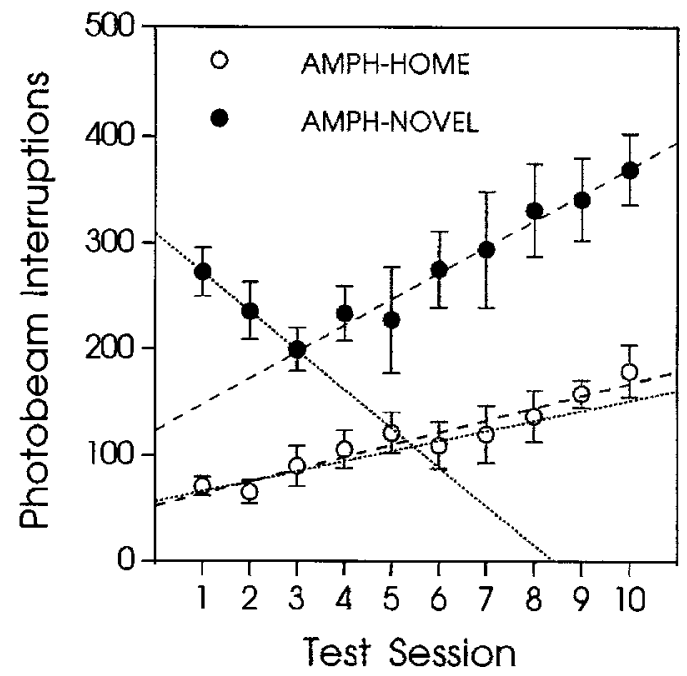

culated for sessions 1-3 (dotted lines) and sessions 3-10 (dashed lines). In group AMPH-HOME there was a linear increase in locomotor activity over sessions 1-10 (slope coefficient: 11.5, $P<0.0001$; $r^{2}=0.93$, mean $r^{2}$ for individual rats $=0.54 \pm 0.09$ ), and no difference in the slope coefficients between sessions $1-3$ and 3-10 (9.5 \pm 9.23 vs. $11.28 \pm 2.39 ; t=0.163, P=0.88$ ). In group AMPH-NOVEL there was a marked difference in the slope coefficients calculated for sessions $1-3$ vs. sessions $3-10$ ( -36.5 vs. $24.53 \pm 4.67$; paired $t$-test: $t=3.96, P<0.03$ ). For sessions $1-3$ there was a linear decrease in locomotor activity (slope coefficient: $-36.5, P=0.005 ; r^{2}=1.0$; mean $r^{2}$ for individual rats $=0.85 \pm 0.06$ ), and for sessions $3-10$ a linear increase in locomotor activity (slope coefficient: 24.5, $P<0.0001 ; r^{2}=0.97$; mean $r^{2}$ for individual rats $\left.=0.70 \pm 0.06\right)$. In addition, the differences in slope coefficients in the later sessions (4-10 in the saline groups; $3-10$ for the amphetamine groups) in the four groups were assessed by a one-way ANOVA $(F 3,16=17.47$, $P<0.0001$ ), followed by Fisher's PLSD tests that revealed a significant difference between group AMPH-NOVEL and all other groups (all $P_{\mathrm{s}}<0.005$ )

first one we are aware of to directly assess the influence of environment (home versus novel) on development of sensitization, when the physical characteristics of the two environments were held constant.

Effects of environment on the acute psychomotor stimulant effects of amphetamine

It is not clear what mechanism(s) accounts for the effects of environment reported here on the acute response to amphetamine. One simple-minded explanation for the effect of environment on the acute response to amphetamine is that the behavioral activating effects associated with exposure to a novel environment add to the behavioral activating effects of amphetamine. In support of this, it was found in experiment 2 that exposure to the novel environment alone was sufficient to produce a large increase in locomotor activity (Fig. 3). This is not, however, a sufficient explanation. First, the behavioral response to amphetamine was larger in the novel environment than at home even after subtracting the locomotor response to saline in 
the novel environment. Second, in experiment 1 exposure to the novel environment alone (i.e., saline in the novel environment) produced negligible rotational behavior, but there was still a large effect of environment on the psychomotor activating effects of amphetamine (see Fig. 1). Thus, in experiment 1, the effects of the novel environment clearly did not sum with those of amphetamine. Therefore, the combined effects of amphetamine and exposure to a novel environment appear to be in some sense "superadditive"; that is, due to an interaction between the effect of the environment and the effect of amphetamine.

It is possible that exposure to the novel environment in NOVEL rats enhanced the acute psychomotor activating effects of amphetamine because this procedure has effects that serve to potentiate the actions of amphetamine; effects not produced by the stimulus properties of the same environment in HOME rats. For example, exposure to a novel environment activates the hypothalamo-pituitary-adrenal (HPA) axis, increasing plasma corticosterone levels (Friedman and Ader 1967; Hennessy et al. 1977) and producing corticotropinreleasing hormone (CRH)-dependent hypertension, tachycardia and hyperthermia (Morimoto et al. 1993). This could potentiate the effects of amphetamine via the action of an adrenal hormone, such as corticosterone, because it has been reported that adrenalectomy reduces the acute locomotor response to amphetamine (Cador et al. 1993a), and to cocaine and morphine (Marinelli et al. 1994). Of course, the facilitatory effect of "stressful" manipulations, such as exposure to a novel environment, could also be due to an interaction between an enhancement in dopaminergic activity produced by "stress" (Thierry et al. 1976; Abercrombie et al. 1989) and that produced by amphetamine. Such an interaction may also explain why stereotyped responses to amphetamine sometimes are potentiated if rats are given the drug immediately following foot-shock (Anisman et al. 1985) or during exposure to cat odors (Williams and Barber 1989).

Effects of environment on the development of amphetamine sensitization

The susceptibility to sensitization could be influenced by factors similar to those that influence the acute response to drugs (although it is important to keep in mind that the acute response to amphetamine and the susceptibility to sensitization often are dissociable). For example, exposure to a novel environment may facilitate sensitization because this procedure activates the HPA axis; i.e., because of some aspect of its action as a "stressor". We are not aware of any studies that have directly assessed the effects of repeated pairings of stress and amphetamine on the development of sensitization, but there are reports that repeated intermittent stress (e.g., tail-pinch or restraint) can itself induce sensitization (for reviews see Robinson 1988; Kalivas and Stewart 1991). The psychomotor activating effects of stimulant drugs (Antelman et al. 1980; Robinson et al. 1985; Badiani et al. 1992), amphetamine-stimulated dopamine release (Wilcox et al. 1986), and the corticosterone response to subsequent stress, such as footshock or novelty (Hennessy and Levine 1977; Hennessy 1991), are all sensitized by prior exposure to repeated stress. Furthermore, the development of sensitization may require activation of the HPA axis, because direct manipulation of the HPA axis influences the development of sensitization. Adrenalectomy is reported to block the development of sensitization produced by amphetamine (Rivet et al. 1989) or restraint stress (Deroche et al. 1992a), and the administration of exogenous corticosterone is reported to sensitize animals to a subsequent amphetamine challenge (Deroche et al. 1992b; Pauly et al. 1993). Corticotropin-releasing hormone has also been implicated in sensitization. Pretreatment with CRH has been reported to potentiate the psychomotor response to amphetamine (Cole and Koob 1989) and to induce long-term sensitization to amphetamine (Cador et al. 1993b). If exposure to a novel environment does enhance sensitization (or the acute response to amphetamine) via activation of the HPA axis and the release of an adrenal hormone, adrenalectomy should abolish the difference between the HOME and NOVEL groups reported here. This prediction remains to be tested.

Alternatively, exposure to a novel environment may enhance sensitization because of the ability of stressors to directly activate DA neurotransmission, as discussed above. In this case giving amphetamine in a novel environment may be equivalent to giving a higher dose of amphetamine, which would be expected to induce greater sensitization. If this is true amphetamine-stimulated DA release should be greater in animals tested in a novel environment, relative to animals tested at home (a prediction that remains to be tested).

Finally, it is possible that sensitization was potentiated when amphetamine was given in a novel environment because the contextual cues associated with this environment acted as a CS+. According to this model, the environmental cues associated with the unconditioned psychomotor activating effects of amphetamine come to acquire $\mathrm{CS}+$ properties, and to elicit a conditioned response (CR). Sensitization is seen as a progressive increase in the CR(s) to the contextual CSs, over-and-above the unconditioned response to the drug. If pairing a novel environment with drug administration facilitated the development of a CR(s) relative to drug administration at home (or if the home environment impeded learning), and if the CR(s) contributed significantly to development of sensitization, this could account for the more rapid sensitization in a novel environment reported here. For example, 
contextual cues associated with the home environment may not function as very effective CSs because they do not reliably predict the drug, whereas contextual cues associated with the novel environment would reliably predict the drug. Indeed, it is well known that conditioning can be disrupted by pre-exposing the animal to the would-be CS (latent inhibition), as would occur in the home environment. Consistent with this, Kiyatkin (1992) found that $120 \mathrm{~min}$ of pre-habituation to the test environment reduced both the acute locomotor response to cocaine and the expression of sensitization. On the other hand, there were a variety of salient cues that did reliably predict the drug in the HOME group, even though they were not cage-related contextual cues. Prior to each injection, animals in the HOME group were picked up by the experimenter, and they received a needle jab, and these stimuli should have served as potent CSs. In addition, the drug itself produces a variety of interoceptive cues that can serve as CSs. It is not obvious, therefore, why there necessarily should be differential acquisition of a $\mathrm{CR}(\mathrm{s})$ in group HOME versus group NOVEL, although we cannot rule this out.

In closing, we must admit we do not know why sensitization was greater in animals that received amphetamine in a novel environment, relative to animals that received the same dose of the drug, in a physically identical environment, but in which they lived. Perhaps all the factors mentioned above are involved, and they interact in complex ways to determine the final behavioral outcome. Whatever the mechanism, the experiments reported here emphasize the extent to which sensitization is influenced by environmental variables.

Acknowledgements This research was supported by a grant from the National Institute on Drug Abuse (\# 02494) to T. E. R. The authors thank Susan Catto and Rebecca White for their assistance in conducting the experiments. Preliminary data from these experiments have been presented at the 19th Meeting of the Society for Neuroscience, 1993.

\section{References}

Abercrombie ED, Keefe KA, Di Frischia DS, Zigmond MJ (1989) Differential effect of stress on in vivo dopamine release in striatum, nucleus accumbens, and medial frontal cortex. J Neurochem 52:1655-1658

Anagnostaras S, Badiani A, Robinson TE (1993) Context-dependent amphetamine sensitization. Soc Neurosci Abstr 19:1241

Anisman H, Hahn B, Hoffman D, Zacharko RM (1985) Stressor invoked exacerbation of amphetamine-elicited perseveration. Pharmacol Biochem Behav 23:173-183

Antelman SM, Eichler AJ, Black CA, Kocan D (1980) Interchangeability of stress and amphetamine in sensitization. Science 207:329-31

Badiani A, Cabib S, Puglisi-Allegra S (1992) Chronic stress induces strain-dependent sensitization to the behavioral effects of amphetamine in the mouse. Pharmacol Biochem Behav 43: 53-60

Bardo MT, Bowling SL, Pierce RC (1990) Changes in locomotion and dopamine neurotrasmission following amphetamine, haloperidol, and exposure to novel environmental stimuli. Psychopharmacology 101:338-343

Beck CHM, Chow HL, Cooper SJ (1986) Initial environment influences amphetamine-induced stereotypy: subsequently environment change has little effect. Behav Neural Biol $46: 383-397$

Breese GR, Traylor TD (1971) Depletion of brain noradrenaline and dopamine by 6-hydroxydopamine. Br J Pharmacol 42: 88-99

Cador M, Dulluc J, Mormede P (1993a) Modulation of the locomotor response to amphetamine by corticosterone. Neuroscience $56: 981-988$

Cador M, Cole BJ, Koob GF, Stinus L, Le Moal M (1993b) Central administration of corticotropin releasing factor induces longterm sensitization to D-amphetamine. Brain Res 606:181-186

Cole BJ, Koob GF (1989) Low doses of corticotropin-releasing factor potentiate amphetamine-induced stereotyped behavior. Psychopharmacology 1989:27-33

Cools AR, Van den Bos R, Ploeger G, Ellenbroek BA (1991) Gating function of noradrenaline in the ventral striatum: its role in behavioural responses to environmental and pharmacological challenges. In: Willner P, Scheel-Krüger J (eds) The mesolimbic dopamine system: from motivation to action, Wiley, Chichester, pp 141-173

Deroche V, Piazza PV, Casolini P, Maccari S, Le Moal M, Simon $H$ (1992a) Stress-induced sensitization to amphetamine and morphine psychomotor effects depend on stress-induced corticosterone secretion. Brain Res 598:343-348

Deroche V, Piazza PV, Maccari S, Le Moal M, Simon H (1992b) Repeated corticosterone administration sensitizes the locomotor response to amphetamine. Brain Res 584: 309-313

Einat H, Szechtman H (1993) Environmental modulation of both locomotor response and locomotor sensitization to the dopamine agonist quinpirole. Behav Pharmacol 4:399-403

Ellinwood EHJ (1971) "Accidental conditioning" with chronic metamphetamine intoxication: implication for a theory of drug habituation. Psychopharmacologia 21:131-138

Ellinwood EHJ, Kilbey MM (1975) Amphetamine stereotypy: the influence of environmental factors and prepotent behavioral patterns on its topography and development. Biol Psychiat 10: $3-16$

Friedman SB, Ader R (1967) Adrenocortical response to novelty and noxious stimulation. Neuroendocrinology 2:209-212

Hefti F, Melamed E, Sahakian BJ, Wurtman RJ (1980a) Circling behavior in rats with partial, unilateral nigro-striatal lesions: effect of amphetamine, apomorphine, and DOPA. Pharmacol Biochem Behay 12:185-188

Hefti F, Melamed E, Wurtman RJ (1980b) Partial lesions of the dopaminergic nigrostriatal system in rat brain: biochemical characterization. Brain Res 195:123-137

Hennessy MB (1991) Sensitization of the plasma corticosterone response to novel environments. Physiol Behav 50:1175-1179

Hennessy MB, Levine S (1977) Effects of various habituation procedures on pituitary-adrenal responsiveness in the mouse. Physiol Behav 18:799-802

Hennessy JW, Levin R, Levine S (1977) Influence of experiential factors and gonadal hormones on pituitary-adrenal response of the mouse to novelty and electric shock. J Comp Physiol Psychol 91:770-777

Hinson RE, Poulos CX (1981) Sensitization to the behavioral effects of cocaine: modification by Pavlovian conditioning. Pharmacol Biochem Behav 15: 559-562

Hirabayashi M, Alam MR (1981) Enhancing effect of methamphetamine on ambulatory activity produced by repeated administration in mice. Pharmacol Biochem Behav 15: 925-932

Hoffman DC, Wise RA (1992) Locomotor activating effects of the D2 agonist bromocriptine show environment-specific sensitization following repeated injections. Psychopharmacology 107 : $277-284$ 
Kalivas PW, Stewart J (1991) Dopamine transmission in the initiation and expression of drug- and stress-induced sensitization of motor activity. Brain Res Rev 16:223-244

Kiyatkin EA (1992) State-dependent peculiarities of cocaineinduced behavioral sensitization and their possible reasons. Int J Neurosci 67: 93-103

Marinelli M, Piazza PV, Deroche V, Maccari S, Le Moal M, Simon H (1994) Corticosterone circadian secretion differentially facilitates dopamine-mediated psychomotor effect of cocaine and morphine. J Neurosci 14:2724-2731

Mattingly BA, Gotsick JE (1989) Conditioning and experiential factors affecting the development of sensitization to apomorphine. Behav Neurosci 103:1311-1317

Mazurski EJ, Beninger RJ (1987) Environment-specific conditioning and sensitization with $(+)$-amphetamine. Pharmacol Biochem Behav 27:61-65

Morimoto A, Nakamori T, Morimoto K, Tan N, Murakami N (1993) The central role of corticotrophin-releasing factor (CRF41) in psychological stress in rats. J Physiol 460:221-229

Pauly JR, Robinson SF, Collins AC (1993) Chronic corticosterone administration enhances behavioral sensitization to amphetamine in mice. Brain Res 620:195-202

Piazza PV, Deminière JM, Le Moal M, Simon H (1989) Factors that predict individual vulnerability to amphetamine self-administration. Science 245:1511-1513

Post RM, Lockfeld A, Squillace KM, Contel NR (1981) Drug-environment interaction: context dependency of cocaine-induced behavioral sensitization. Life Sci 28:755-760

Rivet JM, Stinus L, Le Moal M, Mormede P (1989) Behavioral sensitization to amphetamine is dependent on corticosteroid receptor activation. Brain Res 498:149-153

Robinson TE (1984) Behavioral sensitization: characterization of enduring changes in rotational behavior produced by intermittent injections of amphetamine in male and female rats. Psychopharmacology 84:466-475

Robinson TE (1988) Stimulant drugs and stress: factors influencing individual differences in the susceptibility to sensitization. In: Kalivas PW, Barnes C (eds) Sensitization in the nervous System, Telford Press, Caldwell, N.J, pp 145-173

Robinson TE, Becker JB (1986) Enduring changes in brain and behavior produced by chronic amphetamine administration: a review and evaluation of animal models of amphetamine psychosis. Brain Res Rev 396:157-98

Robinson TE, Berridge KC (1993) The neural basis of drug craving: an incentive-sensitization theory of addiction. Brain Res Rev 18:247-291

Robinson TE, Angus AL, Becker JB (1985) Sensitization to stress: the enduring effects of prior stress on amphetamine-induced rotational behavior. Life Sci 37:1039-1042

Russel RL, Pihl RO (1978) The effect of dose, novelty, and exploration on amphetamine-produced stereotyped behavior. Psychopharmacology 60:93-100

Sahakian BJ, Robbins TW, Morgan MJ, Iversen SD (1975) The effects of psychomotor stimulants on stereotypy and locomotor activity in socially-deprived and control rats. Brain Res 84:195-205
Schallert T, De Ryck M, Teitelbaum P (1980) Atropine stereotypy as a behavioral trap: a movement subsystem and electroencephalographic analysis. J Comp Physiol Psychol 94: 1-24

Schiff SR (1982) Conditioned dopaminergic activity. Biol Psychiatry $17: 135-154$

Segal DS, Schuckit MA (1983) Animal models of stimulant-induced psychosis. In: Creese I (ed) Stimulants: neurochemical, behavioral and clinical perspectives. Raven Press, New York, pp 131-167

Stewart J, Badiani A (1993) Tolerance and sensitization to the behavioral effects of drugs. Behav Pharmacol 4:289-312

Stewart J, Vezina P (1987) Environment-specific enhancement of the hyperactivity induced by systemic or intra-VTA morphine injections in rats preexposed to amphetamine. Psychobiology $15: 144-153$

Stewart J, Vezina P (1988) Conditioning and behavioral sensitization. In: Kalivas PW, Barnes CD (eds) Sensitization in the nervous system. Telford Press, Caldwell, N.J, pp 207-224

Stewart J, Vezina P (1991) Extinction procedures abolish conditioned stimulus control but spare sensitized responding to amphetamine. Behav Pharmacol 2:65-71

Sullivan R, Dogaru C, Szechtman H (1992) Constriction of environmental space and the behavioral response to the dopamine agonist quinpirole. Pharmacol Biochem Behav 43:1217-1219

Terlouw EMC, De Rosa G, Lawrence AB, Illius AW, Ladewig J (1992) Behavioural responses to amphetamine and apomorphine in pigs. Pharmacol Biochem Behav 43:329-340

Thierry AM, Tassin JP, Blanc G, Glowinski J (1976) Selective activation of the mesocortical DA system by stress. Nature 263:242-243

Tilson HA, Rech RA (1973) Conditioned drug effects and absence of tolerance to $d$-amphetamine induced motor activity. Pharmacol Biochem Behav 1: 149-153

Ungerstedt U, Arbuthnott GW (1970) Quantitative recording of rotational behavior in rats after 6-hydroxy-dopamine lesions of the nigrostriatal dopamine system. Brain Res 24:485-493

Vezina P, Stewart $J$ (1984) Conditioning and place-specific sensitization of increases in activity induced by morphine in the VTA. Pharmacol Biochem Behav 20:925-934

Weiss SR, Post RM, Pert A, Woodward R, Murman D (1989) Context-dependent cocaine sensitization: differential effect of haloperidol on development versus expression. Pharmacol Biochem Behav 34:655-661

Wilcox RA, Robinson TE, Becker JB (1986) Enduring enhancement in amphetamine-stimulated striatal dopamine release in vitro produced by prior exposure to amphetamine or stress in vivo. Eur J Pharmacol 124:375-376

Williams JL, Barber RG (1989) Effects of cat exposure and cat odors on subsequent amphetamine-induced stereotypy. Pharmacol Biochem Behav 36:375-380

Willner P, Papp M, Cheeta S, Muscat R (1992) Environmental infiuences on behavioural sensitization to the dopamine agonist quinpirole. Behav Pharmacol 3:43-50 